\title{
Naturaleza Jurídica y Competencias específicas de las Corporaciones Autónomas Regionales dentro de la Nueva Estructura del Poder Público Colombiano
}

\section{INTRODUCCIÓN}

La Carta Política de 1991 previó en su contenido orgánico, la estructura del Estado colombiano, ocupándose de reseñar la estructura tradicional del poder público, a partir de la rama ejecutiva, legislativa y judicial. Con todo, ello no agotó tal previsión. En efecto, dentro del mismo artículo 113, señaló el constituyente que al lado de los órganos que las integran, existen otros, autónomos e independientes, para el cumplimiento de las demás funciones del Estado, previsión que sirvió de base, no solo para abandonar la estructura tripartita del poder que acompaña desde sus inicios el Estado moderno sino también para dar lugar al surgimiento, tanto directo (en la Constitución) como indirecto (por delegación de esta) de órganos autónomos que también cumplen funciones a cargo del Estado como superestructura.

A partir de este texto, surgieron entonces algunas entidades completamente autónomas, con o sin personería jurídica, por supuesto de derecho público, creadas por la Constitución o con sujeción a ella, que sin pertenecer a las tradicionales ramas del poder público, cumplen hoy funciones públicas específicas que no dependen de las orientaciones, decisiones o directrices de la suprema autoridad administrativa ni están adscritos o vinculados a ninguna dependencia de la administración en términos de jerarquía. Empero, es necesario reconocer que dicha autonomía no implica el desconocimiento de los principios de colaboración y concurrencia con otros órganos y con las demás ramas del poder público, pues al fin de cuentas se trata de órganos creados para atender necesidades que comúnmente debe resolver el Estado como unidad.

Las Corporaciones Autónomas Regionales constituyen un ejemplo de este tipo de órganos autónomos. La creación de la Corporación Autónoma Regional del Rio Grande de la Magdalena, la dio justamente el artículo 331 constitucional, el cual le asignó ciertas funciones específicas, entre ellas, la recuperación de la navegación y de la actividad portuaria, la adecuación y la conservación de tierras, la generación y

${ }^{1}$ Abogado de la Universidad Cooperativa de Colombia Seccional Neiva, especialista en Derecho penal y ciencias criminológicas de la Universidad Externado de Colombia, especialista en Derecho administrativo de la Universidad Externado de Colombia, Candidato a Magister en Derecho administrativo de la Universidad Externado de Colombia, Estudio especial Sistema Penal Acusatorio de la Universidad Externado de Colombia, Docente de tiempo completo por concurso de la Universidad Surcolombiana de Neiva y Coordinador del área de Derecho penal, profesor de la Universidad Cooperativa de Colombia Seccional Neiva, Director del Grupo de Investigaciones "Nova luris" de la Universidad Cooperativa, miembro del grupo de investigación "Nuevas Visiones del Derecho" de la Universidad Surcolombiana. Director de Centro de Investigaciones de la Universidad Cooperativa de Colombia Seccional Neiva. Director de la Revista Ale Kuma. E mail: helmasacu@gmail.com; helmasacu@hotmail.com 
distribución de energía y el aprovechamiento y preservación del ambiente, los recursos ictiológicos y demás recursos naturales renovables; al lado de esta, el numeral 7 del artículo 150 superior, facultó al Congreso de la República para que a través de la Ley creara otras Corporaciones Autónomas, delegando en él la facultad para establecer su funcionamiento y estructura interna.

Adicionalmente y como quiera que la misma Carta Política le atribuyó al legislador la facultad de regular su estructura interna (Artículo 150 numeral 7), sería la Ley 99 de 1993 la encargada de hacer efectiva este mandato, ocupándose de definirles como "... ente corporativo de carácter público, creado por Ley, integrado por las entidades territoriales, que por sus características constituyen geográficamente un mismo ecosistema 0 conforman una unidad geopolítica, biogeográfica - hidrogeográfica, dotados de autonomía administrativa y financiera, patrimonio propio, personería jurídica, encargados dentro del área de su jurisdicción, del medio ambiente y los recursos naturales renovables y propender por su desarrollo sostenible, de conformidad con las disposiciones legales y las politicas del Medio Ambiente".

A partir de esta contextualización general y normativa de este nuevo organismo de carácter público, surge, a nuestro modo de ver, una problemática particular que merece especial atención: la relativo a la determinación de la naturaleza juridica de estas organizaciones y las competencias funcionales específicas que poseen.

La pertinencia de esta problemática aflora de la confusa manera en que se suele confundir, funciones de órganos del orden nacional como el Ministerio de Vivienda y Medio Ambiente, las entidades territoriales y las mismas dependencias de estas en tanto encargadas del cuidado, preservación y mejoramiento del medio ambiente, más aún cuando por disposición de la misma norma general que ordenó su creación, el Consejo Directivo de estas entidades (máximo órgano de dirección), se compone de miembro escogidos de entre las mismas entidades territoriales, lo que sugiere entonces ocuparse del tema, nunca antes tratado por la reciente creación de estas organizaciones.

La propuesta se concretará entonces a establecer si la autonomía e independencia de las que cuando menos en teoría se les ha dotado, se refleja en su funcionamiento y estructura interna o si por el contrario, estamos antes órganos que actúan bajo las sombras de la rama ejecutiva, propuesta para la cual se abordará inicialmente lo relativo a los órganos autónomos e independientes, a continuación nos referiremos a las Corporaciones Autónomas Regionales y finalmente, nos ocuparemos de la situación problemática que surge de su configuración normativa y funcionamiento interno para hacer nuestras conclusiones sobre el particular.

\section{DE LOS ÓRGANOS AUTÓNOMOS}

\section{E INDEPENDIENTES}

Claro está, que la Constitución Política colombiana superó la estructura tripartita del poder concebida y consolidada en el Estado moderno, dando paso, tal vez indirecta e involuntariamente, al surgimiento de nuevas instituciones y órganos -autónomos e independientes- encargados de cubrir otro tipo de funciones en orden a satisfacer las necesidades, cada vez mayores de los asociados, las cuales no pueden ser cubiertas a partir de las estructuras tradicionales de la ramas ejecutiva, legislativa y judicial.

Con ese norte, el constituyente de 1991, advertido de la necesidad de adecuar las estructuras públicas a las nuevas exigencias del servicio público, ajustó jurídicamente los esquemas tradicionales para aceptar que el derecho y por supuesto, el Estado, debe proveer por aceptar la existencia de otros frentes igualmente importantes de la dinámica social y en ese sentido, flexibilizar sus estructuras para tratar de ir a la par de las mismas y ofrecer alternativas de cubrimiento consistentes, no obstante que ello traiga consigo el dejar a un lado 
las especiales atribuciones que antes tienen en su seno las ramas especiales.

Fue entonces el artículo 113 superior el encargado de abrir la posibilidad de estatuir nuevos órganos públicos independientes, encargados de efectivizar el cumplimiento de sus funciones, indicando:

"Son Ramas del Poder Público, la Legislativa, la Ejecutiva y la Judicial. Además de los órganos que las integran, existen otros, autónomos e independientes, para el cumplimiento de las demás funciones del Estado. Los diferentes órganos del Estado tienen funciones separadas pero colaboran armónicamente para la realización de sus fines" (Negrillas fuera de texto original).

Ocurre entonces que acudiendo la dinámica social, alimentada en forma determinante por el crecimiento poblacional, se hace cada vez más compleja y en medio de ello, crece en índices insostenibles la demanda de servicios oficiales 0 cuando menos, comunales cuya responsabilidad recae esencialmente en el Estado, depositario electo de dichas expectativas, las cuales ya no se encuentran reducidas a administrar a los gobernados, dictar normas de conducta de carácter general para garantizar la convivencia pacífica y resolver como heterocomponedor los conflictos. Hoy más que ayer, el mismo crecimiento y madurez de la sociedad exige ocuparse un poco más de brindar condiciones de vida digna a las personas, colaborar en la defensa de sus derechos, asignar funciones específicas $y$ al margen de las tres tradicionales ramas del poder público, sugiriéndose así la creación de organismos independientes como el Ministerio público y dentro de él, la Procuraduría General de la Nación y la Defensoría del Pueblo, la Registraduría Nacional del Estado Civil, el Banco de la República, la Fiscalia General de la Nación, entre otros, que en general no son más que entidades sin o con personería jurídica, de derecho público, creadas por la Constitución o con sujeción a ella por la Ley, que al tiempo que no pertenecen a alguna de las tradicionales Ramas del poder público, no dependen de las orientaciones, decisiones o directrices de la suprema autoridad administrativa ni están adscritos o vinculados a ninguna dependencia de la administración en términos de jerarquía.

Con todo y reconocido como está, que dichos órganos no pertenecen a ninguna de las ramas tradicionales del poder público, gozando por ende de cierta autonomía e independencia, no por ello se les debe tener como ajenas al actuar estatal, debiendo en todo caso contribuir y colaborar en el cometido público para fines de dar cumplimiento a los fines del Estado y en general a los propósitos de la función administrativa.

\section{IAS CORPORACIONES AUTÓNOMAS REGIONALES}

Ahora bien, en el ámbito de la garantía de intereses de común aprecio, fuente generadora de condiciones de convivencia armónica, se empieza a sentir la necesidad de contar con órganos que de manera autónoma $e$ independiente se ocupen esencial y únicamente de protegerles para el beneficio conjunto, otorgándoseles así una misión propia al tiempo que se les dota de autonomía y otros instrumentos suficientes para el cumplimiento de su cometido.

Surgieron entonces con la Constitución Política de 1991, las Corporaciones Autónomas Regionales, la del Río Grande de la Magdalena (Artículo 331), creada directamente por el constituyente, encargada de la recuperación de la navegación, la actividad portuaria, la adecuación y la conservación de tierras, la generación y distribución de energía y el aprovechamiento y preservación del ambiente los recursos ictiológicos y demás recursos naturales renovables y cuyo régimen, por disposición del mismo texto constitucional, corresponde desarrollarlo al legislador; y, las demás Corporaciones Autónomas Regionales, cuya atribución de creación fue conferida al legislador, en el numeral 7 del artículo 150 superior, delegándose en él la potestad de reglamentar su creación y funcionamiento dentro de un régimen de autonomía. 
Sería entonces la Ley 99 del 22 de diciembre de 1993 "Por la cual se crea el Ministerio del Medio Ambiente, se reordena el Sector Público encargado de la gestión y conservación del medio ambiente y los recursos naturales renovables, se organiza el Sistema Nacional Ambiental, SINA y se dictan otras disposiciones", la encargada de operativizar el texto constitucional. Dicho compendio normativo les definió como "entes corporativos de carácter público, creados por Ley, integrados por las entidades territoriales, que por sus características constituyen geográficamente un mismo ecosistema o conforman una unidad geopolítica, biogeográfica - hidrogeográfica, dotados de autonomía administrativa y financiera, patrimonio propio, personería jurídica, encargados dentro del área de su jurisdicción, del medio ambiente y los recursos naturales renovables y propender por su desarrollo sostenible, de conformidad con las disposiciones legales y las politicas del MedioAmbiente".

Su estructura, como se advierte, corresponde enteramente a la de un órgano descentralizado de la administración pública y concretamente de la rama ejecutiva del poder público, no obstante ser un órgano autónomo, o dicho en otros términos, cabeza de su propia misión. En efecto, poseen autonomía administrativa y financiera, patrimonio propio, personeria jurídica y ante todo unos órganos de dirección y administración, representados en la Asamblea Corporativa, el Consejo Directivo y el Director General.

Tal configuración estructural les dotó entonces de una muy bien anunciada autonomía, al punto que el mismo artículo 4 de la Ley 99 de 1993, al definir el Sistema Nacional Ambiental SINA, como el conjunto de orientaciones, normas, actividades, recursos, programas e instituciones que permiten la puesta en marcha de los principios generales ambientales contenidos en esta Ley, dispuso que en su integración concurrían, entre otros componentes, "... 3) Las entidades del Estado responsables de la politica y de la acción ambiental, señaladas en la Ley...", señalándose además que para todos los efectos, la jerarquía en su interior tendría como órgano superior máximo, al Ministerio del Medio Ambiente, las Corporaciones
Autónomas Regionales y por último, los Departamentos y Distritos o municipios.

La Corte Constitucional, en sentencia C-216 de abril 28 de 1994, sostuvo sobre el particular y en referencia a estas Corporaciones, que si bien el Estado unitario supone el principio de la centralización política, que se traduce en unidad de mando supremo, unidad en todos los ramos de la legislación, unidad en la administración de justicia $y$, en general, unidad en las decisiones de carácter político que tienen vigencia para todo el espacio geográfico nacional, ello no representaba la imposibilidad de que junto a ella, coexistieran órganos independientes:

\section{"...Pero la centralización política no es incompatible} con la descentralización administrativa, ni con la autonomía de las entidades regionales. Por el contrario, la tendencia en los Estados unitarios en el mundo contemporáneo ha sido la de vigorizar estos principios. La palabra "descentralización" se emplea en sentido genérico y en sentido técnico. De acuerdo con el primero, se le da ese nombre a todo proceso que traslada a asuntos de la capital del Estado a las entidades seccionales o locales, cualquiera que sea su índole; así se habla de descentralización fiscal, económica o industrial. En sentido técnico jurídico, la descentralización significa traslado de competencias de carácter administrativo a manos de autoridades regionales olocales".

En ese mismo sentido la Corte Constitucional en Sentencia C - 517 de 1992 (M.P. Dr. Ciro Angarita Barón), "La autonomía, por el contrario, se ejerce dentro de un marco jurídico determinado, que va variando a través del tiempo y que puede ser más o menos amplio...

Retomando entonces lo sostenido por la Corte Constitucional, se tiene que el objeto de estas Corporaciones, se orienta a la ejecución autónoma e independiente de las políticas, planes, programas y proyectos sobre medio ambiente y recursos naturales renovables, así como dar cumplida y oportuna aplicación a las disposiciones legales vigentes sobre su disposición, administración, manejo y aprovechamiento, conforme a las 
regulaciones, pautas y directrices expedidas por el Ministerio del MedioAmbiente.

\section{ASPECTOS PROBLEMÁTICOS}

Con todo, tal y como se advirtió al comienzo de esta disertación, sorprende que con tal claro panorama, el legislador no hubiese tenido especial cuidado en delimitar el ámbito de actuación de estos entes. En efecto, repasado el no poco marco de responsabilidades que corresponde a los entes públicos y dentro de él especialmente a los entes territoriales, se puede advertir sin mayores dificultades una cierta coincidencia de atribuciones - mejor aún, un marco de competencias y funciones bastante ambiguo que termina no solo por cuestionar la aparente radicalidad en el otorgamiento de autonomía a estos entes, sino también, la misma autonomía, en tanto diferírseles

\section{CORPORACIONES AUTÓNOMAS REGIONALES}

Participar con los demás organismos y entes competentes en el ámbito de su jurisdicción, en los procesos de planificación $y$ ordenamiento territorial a fin de que el factor ambiental sea tenido en cuenta en las decisiones que se adopten (Numeral 5 artículo 31 Ley 99 de 1993).

Imponer y ejecutar a prevención y sin perjuicio de las competencias atribuidas por la ley a otras autoridades, las medidas de policía y las sanciones previstas en la ley, en caso de violación a las normas de protección ambiental y de manejo de recursos naturales renovables y exigir, con sujeción a las regulaciones pertinentes, la reparación de daños causados (Numeral 17 artículo 31 Ley 99 de 1993).

Ejecutar las políticas, planes y programas nacionales en materia ambiental definidos por la ley aprobatoria del Plan Nacional de Desarrollo y del Plan Nacional de Inversiones o por el Ministerio del Medio Ambiente, así como los del orden regional que le hayan sido confiados conforme a la ley, dentro del ámbito de su jurisdicción (Numeral 1 artículo 31 Ley 99 de 1993).

Promover y desarrollar la participación comunitaria en programas de protección ambiental, de desarrollo sostenible y de manejo adecuado de los recursos naturales renovables (Numeral 3 artículo 31 Ley 99 de 1993). competencias de forma subsidiaria, concurrente y hasta dependiente de directrices de órganos de la Administración Central como el Ministerio de Medio Ambiente, Vivienda y desarrollo Rural.

En cuanto hace a lo primero, es sabido que el municipio, como ente básico del accionar administrativo, es el encargado de un cúmulo de competencias dentro del territorio que le corresponde, algunas de las cuales tiene que ver con la preservación del medio ambiente en todos sus niveles, ámbito de actuación que en veces, coincide con el asignado a las Corporaciones Autónomas Regionales. A continuación se reseñan algunos ejemplos de esta inconsistencia de regulación que aún cuando tan solo de modo insular ha logrado colocar en aprietos a las autoridades, no deja de ser un verdadero cuestionamiento a la política de definición de los espectros de actuación de todos y cada uno de los órganos del Estado:

\section{MUNICIPIOS}

Planificar el desarrollo económico, social y ambiental de su territorio, de conformidad con la ley $y$ en coordinación con otras entidades (Numeral 4 artículo 3 Ley 136 de 1994).

Velar por el adecuado manejo de los recursos naturales y del medio ambiente, de conformidad con la ley (Numeral 6 artículo 3 Ley 136 de 1994).

Establecer programas permanentes para el conocimiento, promoción y protección de los valores democráticos, constitucionales, institucionales, cívicos y especialmente el de la solidaridad social de acuerdo con los derechos fundamentales; los económicos, los sociales y culturales; y los colectivos y del medio ambiente (Artículo 142 Ley 136 de 1994). 
Evidenciado lo anterior, extraña aún más que la aludida autonomía e independencia que parecen tener, se vea empañada esta vez, no solo por la jerarquía subordinada que tienen para con el Ministerio del Medio Ambiente, Desarrollo y Vivienda en materia ambiental, como miembros del Sistema Nacional Ambiental, sino también, la remisión que constantemente se hace a las directrices de esta cartera central para efectos del ejercicio de algunas de sus funciones.

En efecto, dentro del ámbito de su competencia territorial y de acuerdo a lo establecido en el numeral 2 del artículo 31 de la Ley 99 de 1993, dichas Corporaciones constituyen la máxima autoridad ambiental, claro está, "... conforme los criterios y directrices trazadas por el Ministerio del Medio Ambiente...". Incluso luego, el numeral 14 de dicho artículo 31 de la Ley 99 de 1993, les encarga de "... 14) Ejercer el control de la movilización, procesamiento y comercialización de los recursos naturales renovables en coordinación con las demás Corporaciones Autónomas Regionales, las entidades territoriales $y$ otras autoridades de policía, con conformidad con la ley y los reglamentos; $y$ expedir los permisos, licencias y salvoconductos para la movilización de recursos naturales renovables..." y luego el numeral 15 les asigna el "...15) Administrar, bajo la tutela del Ministerio del Medio Ambiente las áreas del Sistemas de Parques Nacionales que ese Ministerio les delegue. Esta administración podrá hacerse con la participación de las entidades territoriales y de la sociedad civil...".

Yes que desde la misma perspectiva constitucional surgen enormes aportes a las dudas expuestas a propósito de la aludida autonomía de que gozan estos entes. Si bien se observa, el numeral 7 del artículo 150 constitucional que previó la posibilidad de su creación, se encabeza y concluye con una amplia referencia a órganos de la administración central y descentralizada de la rama ejecutiva del poder público, lo que sugeriría entonces que cuando se ejerciera por parte del Congreso la facultad de determinar la estructura de esta rama y entre ella, de las precitadas Corporaciones, estaría realizando la competencia que se le atribuyó sobre la organización del ejecutivo, lo que sin duda alguna les restaría la independencia anunciada, mostrándoles simplemente como órganos descentralizados. $^{2}$

Claro, lo anterior sin olvidar que al lado de ello, el patrimonio de las Corporaciones se compone en buena medida de dineros aportados por la Nación, tal como lo señalan los artículos 42 y siguientes de la ley 99 de 1993 y el mismo artículo 317 de la Constitución Política:

“Artículo 317. Sólo los municipios podrán gravar la propiedad inmueble. Lo anterior no obsta para que otras entidades impongan contribución de valonización.

"La ley destinará un porcentaje de estos tributos, que no podrá exceder del promedio de las sobretasas existentes, a las entidades encargadas del manejo y conservación del ambiente y de los recursos renovables, de acuerdo con los planes de desarrollo de los municipios del área de su jurisdicción."( se subraya)

Y es que la confusión se hace aún más notoria al apreciar los mismos derroteros jurisprudenciales que en la materia se han trazado. En efecto, la Corte Constitucional ha sostenido expresamente:

“... La existencia de corporaciones autónomas regionales dentro de nuestro régimen constitucional, obedece, lo mismo que la de las entidades terntoriales, al concepto de descentralización. Es sabido que la Constitución consagra varias formas de descentralización, entre ellas la que se fundamenta en la división territorial del Estado, y la que ha sido llamada descentralización por servicios, que implica la existencia de personas jurídicas dotadas de autonomía jurídica,

\footnotetext{
2Empero lo dicho, lo cierto es que la Ley 489o del 29 de diciembre de 1998, a través de la cual se dictaron normas sobre la organización y funcionamiento de las entidades del orden nacional dentro de la rama ejecutiva, no se ocupó en ninguno de sus apartados de este tipo de instituciones, lo que entonces permite concluir que la mención a ellas hecha en el pluricitado numeral 7 del artículo 150 no es más que una coincidencia que en nada incide a la hora de cuestionar su independencia.
} 
patrimonial y financiera, "articuladas jurídica y funcionalmente con el Estado, a las cuales se les asigna por la ley unos poderes jurídicos especificos" o facultades para la gestión de ciertas competencias. "Dentro de esta última modalidad de descentralización se comprenden, según el art. 150-7, diferentes organismos, como los establecimientos públicos, las corporaciones autónomas regionales, las empresas industriales y comerciales del Estado y las sociedades de economia mixta, que se instituyen como una respuesta a la necesidad de cumplir distintas formas de gestión de la actividad estatal y de especificos cometidos, algunos tradicionales, otros novedosos, pero necesarios para el logro de las finalidades propias del Estado Social de Derecho." ${ }^{3}$

Y sorprende porque el fenómeno de la descentralización implica la existencia de un poder central, que ejerce un control de tutela sobre los órganos descentralizados, cosa que no ocurre -cuando menos teóricamente- para con las Corporaciones Autónomas Regionales. $\mathrm{Ha}$ terminado entonces la Corte por asignarles la calidad de entidades administrativas del orden nacional que pueden representar a la Nación dentro del régimen de autonomía que les garantiza el numeral 7 del artículo 150 de la Constitución, concebidas para la atención y el cumplimiento autónomo de muy precisos fines asignados por la Constitución sin que estén adscritas ni vinculadas a ningún ministerio o departamento administrativo, pero a continuación, precisa que "... en la medida definida por el legislador, respetando su autonomía financiera, patrimonial, administrativa y política, pueden ser agentes del Gobierno Nacional, para cumplir determinadas funciones autónomas en los casos señalados porla ley....".

Tal inconsistencia, que no hace otra cosa que restarles autonomía y ubicarles como entes descentralizados, permite entonces acrecentar las dudas acerca de la verdadera autonomía e independencia con que se les anuncia desde el mismo texto constitucional.
Lo que en cambio no es casualidad, es la configuración interna de sus órganos. En efecto, el artículo 26 de la Ley 99 de 1993, dispuso que el Consejo Directivo de las mismas sería su órgano de administración y estaría conformado por:

“a. El gobemador o los gobernadores de los departamentos sobre cuyo territorio ejerza jurisdicción la CorporaciónAutónoma Regional, o su delegado o delegados. Corresponderá al gobernador o a su delegado presidir el Consejo Directivo. Si fuesen varios los gobemadores, los estatutos definirán 10 relativo a la presidencia del Consejo Directivo;

b. Un representante del Presidente de la República;

c. Un representante del Ministro del Medio Ambiente.

d. Hasta cuatro (4) alcaldes de los municipios comprendidos dentro del territorio de la jurisdicción de la corporación, elegidos por la Asamblea Corporativa, para períodos de un (1) año por el sistema de cuociente electoral, de manera que queden representados todos los departamentos o regiones que integran la corporación. Si el territorio de la Corporación comprendiese un número plural de departamentos, la participación será definida en forma equitativa de acuerdo con el reglamento que al efecto expida el Gobierno Nacional;

e. Dos (2) representantes del sector privado;

f. Un (1) representante de las comunidades indigenas o etnias tradicionalmente asentadas en el territorio de jurisdicción de la Corporación, elegido por ellas mismas;

g. Dos (2) representantes de las entidades sin ánimo de lucro, que tengan su domicilio en el

${ }^{3}$ Sentencia C-596 del 21 de octubre de 1998 (Referencia: Expediente D-2021), a propósito de la demanda de inconstitucionalidad contra los artículos 23 y 31 numeral $2^{\circ}$ de la Ley 99 de 1993 , con ponencia del Dr. VLADIMIRO NARANJO MESA.

${ }^{4}$ Sentencia C-596 del 21 de octubre de 1998 (Referencia: Expediente D-2021), a propósito de la demanda de inconstitucionalidad contra los artículos 23 y 31 numeral $2^{\circ}$ de la Ley 99 de 1993, con ponencia del Dr. VLADIMIRO NARANJO MESA. 
área de jurisdicción de la Corporación y cuyo objeto principal sea la protección del medio ambiente y los recursos naturales renovables, elegido porellas mismas...."

Como se observa, más de la mitad de los miembros permanentes de dicho Consejo Directivo, lo constituyen representantes legales de órganos centrales o descentralizados de la rama ejecutiva del poder público, lo que sin duda alguna impone el que direccionamiento así estructurado, esté dominado por la misma, cuestionándose entonces la aludida autonomía e independencia, resquebrajada en su mismo interior.

En definitiva, podría concluirse, a nuestro modo de ver, que aunque se trata de órganos autónomos e independientes, con funciones especificamente delimitadas en la Constitución y en la Ley, la regulación normativa aún es ambigua y su operatividad muestra a las Corporaciones Autónomas Regionales como órganos que en buena medida dependen en sus ejecutorias de la rama ejecutiva, lo que desdice de la anunciada autonomía que quiso otorgarles el constituyente primario.

\section{BIBLIOGRAFÍA}

- Corte Constitucional. Sentencia C-578/1999.

- Corte Constitucional. Sentencia C-596/1999.

- Corte Constitucional. Sentencia C-275/1998.

- Corte Constitucional. Sentencia C-150/2003.

- Corte Constitucional. Sentencia C-827/2001..

- Consejo de Estado, Sala de consulta y servicios civil, Concepto del 29 de abril de 1996, Rad. 814

- GARCÍA LLOVET, Enrique, Autoridades Administrativas Independientes y Estado de Derecho en "Revista de Administración Pública - R.A.P" No. 131, Edit. Instituto de Administración Pública, mayo agosto de 1993, Madrid 1993.

- POMED SÁNCHEZ, Luis Alberto, Fundamento y Naturaleza Jurídica de las Administraciones Independientes en "Revista de Administración Pública - R.A.P" No. 132, Edit. Instituto de Administración Pública, septiembre-diciembre de 1993, Madrid 1993.

- RODRÍGUEZ, Libardo, DerechoAdministrativo General y Colombiano, Editorial Temis, 2007.

- RODRÍGUEZ, Libardo, Estructura del poder público en Colombia, Editorial Temis, 2005.

- SANTOFIMIO GAMBOAJaime, Tratado de DerechoAdministrativo, Editorial Externado, 2007. 